\title{
INFECTIOUS KERATITIS IN WESTERN NEPAL: AN EXPERRENGE FROM A TERTIARY CARE HOSPITAL
}

\author{
Shrestha $R^{1}$, Nayak $N^{1}$, Gurung $B^{2}$, Gokhale $S^{1}$
}

${ }^{1}$ Department of Microbiology, Manipal College of Medical Sciences, ${ }^{2}$ Department of Ophthalmology, Himalayan Eye Hospital, Pokhara, Nepal

\begin{abstract}
Corneal blindness is a major public health problem worldwide and infectious keratitis remains a leading cause. The aim was to analyze the microbial etiology of corneal ulcers and to determine the antibiotic susceptibility pattern of bacterial isolates. Among 84 clinically diagnosed cases, 33 (39.3\%) were farmers by occupation. All cases were reviewed for predisposing conditions and clinical severity. Ulcers were categorized as mild in 49 cases moderate in 12 and severe in 23 cases. Predisposing conditions were detected in $65.5 \%$ (55/84) of patients. Forty-two cases showed culture positivity. Among these 42; 25 (29.7\%) yielded fungi, 13(30.1\%) yielded bacteria and the rest 4 (4.7\%) showed mixed growth, accounting for a total of 29 cases showing fungal growth, and 17 demonstrating bacterial growth. Aspergillus spp. (10/29; 34.5\%) were the commonest fungi and Staphylococcus aureus, $(8 / 17 ; 47 \%)$ was the most common among bacteria. Majority i.e $66.7 \%$ (26 of 39) of those having trauma as the predisposing factor developed moderate to severe degree of corneal ulceration as compared to only $20 \%$ (9 of 45) of those without any history of trauma and this difference was found to be statistically significant ( $\mathrm{p}<0.001)$. Interestingly, 20(68.9\%) of 29 cases that yielded fungal growth on culture had previous history of ocular trauma in contrast to only 19 (34.5\%) of 55 who had non-fungal keratitis $(\mathrm{p}=0.003)$. It was also observed that significantly higher number of fungal keratits cases exhibited pronounced degree of clinical severity, as compared to cases without any fungal aetiology $(\mathrm{p}<0.001)$ Topical administration of fourth generation fluoroquinolone eye drops remained the most effective drug of choice as far as the clinical outcome of bacterial keratitis was concerned. Trauma with vegetative matter predisposed to most cases of fungal keratitis. Severe form of ulceration was noticed in patients with fungal infection.
\end{abstract}

\section{KEYWORDS}

Corneal blindness, trauma,

farmers, ulcerative keratitis

\section{CORRESPONDING AUTHOR}

Dr. Rajani Shrestha, Lecturer,

Department of Microbiology

Manipal College of Medical Sciences,

Pokhara, Nepal

Email: rajani_sth7@hotmail.com

ORCID ID: 0000-0001-9499-7478

DOI: https://doi.org10.3126/nmcj.v21i4.27624 


\section{INTRODUCTION}

Corneal ulcer is a potentially vision threatening ocular morbidity, which involves disruption of corneal epithelial layer with involvement of the corneal stroma. ${ }^{1}$ It is one of the major causes of monocular blindness after un-operated cataract in many of the developing nations in Asia, Africa and the Middle East. ${ }^{1,2}$ It can be caused by various pathogens such as bacteria, fungi, viruses and parasites, ${ }^{3}$ bacteria and fungi accounting for majority of cases of corneal opacity. ${ }^{4}$ The prevalence of corneal blindness due to infectious keratitis differs from country to country and even from one population to another, depending upon the general standards of eye care. ${ }^{5}$ The etiology of infective keratitis varies disproportionately among different geographical regions with highest proportion of bacterial keratitis reported from North America, Australia, Netherlands, and Singapore and that of fungal corneal ulcer from India and Nepal. ${ }^{6}$

Many predisposing factors have been implicated in the causation of infectious corneal ulcer. Ocular trauma is a common predisposing factor in developing countries, whereas pre-existing ocular disease and contact lens wear are common risk factors in the developed countries. ${ }^{7,8}$ Etiologic and epidemiologic patterns of corneal ulceration vary with the patient population, geographic location and climatic conditions. ${ }^{9}$ Thus, the aim was to analyze the bacterial and fungal agents causing corneal ulcer among patients presenting to a tertiary care hospital in western Nepal. Secondly, we also attempted to determine the antibiotic susceptibility pattern of bacterial isolates in order to know the existing pattern of antibiotic resistance among the isolates.

\section{MATERIALS AND METHODS}

This was a prospective study conducted at Himalayan Eye Hospital Pokhara and Manipal College of Medical Sciences Pokhara in western Nepal, over a period of 12 months (June 2017 to May 2018). Ethical approval was obtained from the competent authority of the Himalayan Eye Hospital. A total of 84 clinically diagnosed keratitis patients presenting to Himalayan Eye Hospital, a tertiary care eye centre in Pokhara western Nepal over a period of 12 month were investigated. All cases had reported with presenting symptoms of redness, pain, watery discharge, diminution of vision, and photophobia. Patients' written consents were taken with detailed history, including their demographic profile, time of onset of symptoms, predisposing factors if any including corneal injuries (agricultural, non-agricultural, and foreign body injuries), history of contact lens wear, prior antibiotic therapy, steroid use and previous surgery. Detailed clinical examination was performed to look for infiltrates, satellite lesions and hypopyon and the extent and margin of the ulcerative lesion.

Corneal scrapings from all patients were collected from patients attending Himalyan Eye Hospital, under the supervision of experienced clinical microbiologists from a tertiary care teaching hospital (Manipal College of Medical Sciences, Pokhara Nepal), and were processed in Department of Microbiology, Manipal Teaching Hospital, Manipal College of Medical Sciences, Pokhara Nepal. Samples were collected after anaesthetizing the cornea with $0.5 \%$ proparacaine eye drops and waiting for 2-3 minutes. With the help of sterile Kimura spatula cornea was scraped by applying multiple, moderately firm, unidirectional strokes, under slit lamp illumination. Material was collected both from the base as well as from the edge of the ulcer, after retracting the lids properly and after cleaning any discharge or debris from the vicinity of the ulcer. ${ }^{10}$ Material obtained from corneal scraping was directly inoculated onto sheep blood agar, and Mac Conkey agar. Mac Conkey agar plates were incubated aerobically at $37^{\circ} \mathrm{C}$. Blood agar plates were incubated in candle jar providing 5-10 $\% \mathrm{CO}_{2}$. The plates were examined after 24 and 48 $\mathrm{hrs}$. All the bacterial isolates were identified with the help of standard protocol. ${ }^{11}$

Antibiotic sensitivity testing of all bacterial isolates was determined by Kirby Bauer disc diffusion method, ${ }^{11}$ against the following antibiotics (Conc. /disc): amikacin (30 $\mu$ g), gentamicin $(10 \mu \mathrm{g})$, tobramycin $(10 \mu \mathrm{g})$, chloramphenicol (30 $\mu \mathrm{g})$, levofloxacin (10ug) ciprofloxacin $(5 \mu \mathrm{g})$, moxifloxacin (5ug) and cefazolin (30ug) discs (Hi Media, Mumbai, India).

For fungal isolation, materials from corneal scrapings were inoculated onto two sets of Sabouraud's dextrose agar (SDA) with chloramphenicol, one incubated at $25^{\circ} \mathrm{C}$ and the other at $37^{\circ} \mathrm{C}$. The SDA tubes were examined every day during the first week, and thereafter every alternate day up to a maximum period of 3 weeks. In case of any growth same was identified by lactophenol cotton blue wet mount preparation and slide culture technique if needed.12,13 Statistical analyses of data were carried out by applying chi-square test.

\section{RESULTS}

A total of 84 cases of clinically diagnosed infectious keratitis were included in our study. Of these 84 subjects, 50 (59.5\%) were females and 34 (40.5\%) 
were males. The patients ranged in ages between 19 to 91 years. Majority of the patients however belonged to the age group of 41-60 years (38/84, i.e $45.2 \%)$. Thirty-three $(39.3 \%)$ of them were farmers or agricultural workers by occupation, others being housewives (26; 31\%), business professionals $(7 ; 8.3 \%)$ students $(6 ; 7.1 \%)$, laborers (5; 6\%) and office holders (4; $4.8 \%)$; the rest (3; $3.6 \%)$ belonging to miscellaneous category.

\section{Table 1: Predisposing factors in corneal} ulcer cases

\begin{tabular}{|lc|} 
Predisposing factors & $\mathbf{( N = 8 4 )}$ \\
Trauma & $39(46 \%)$ \\
$\quad$ Vegetable matter & 29 \\
$\quad$ Stone & 5 \\
$\quad$ Hair & 2 \\
$\quad$ Others & 3 \\
Previous episodes of keratitis & $\mathrm{Nil}$ \\
Previous surgery & $\mathrm{Nil}$ \\
Others & \\
$\quad$ Steroid use/antibiotic use & 10 \\
$\quad$ Dry eye & $\mathrm{Nil}$ \\
$\quad$ Contact lens & $\mathrm{Nil}$ \\
Systemic illness/malnutrition & 6 \\
Facial palsy & $\mathrm{Nil}$ \\
None identified & 29 \\
\hline
\end{tabular}

All 84 cases were reviewed for predisposing conditions and clinical severity. Ulcers were categorized as mild in 49 cases moderate in 12 and severe in 23 cases according to criteria laid down earlier. ${ }^{14}$ Predisposing conditions were found in $55(65.5 \%)$ of the 84 cases, which are listed vide Table 1.

As shown in Table 2, out of 84 samples examined, culture positivity was seen in $42(50 \%)$. Among these $42 ; 25$ (29.7\%) yielded fungal growth, 13 (30.1\%) yielded bacterial growth and the rest $4(4.7 \%)$ showed mixed growth. Overall there were 17 (20.2\%) bacterial isolates and 29 (34.5\%) fungal isolates. Staphylococcus aureus (47\%; 8/17) was the most common among bacterial isolates followed by Pseudomonas spp., (11.7\%; 2/17), Acinetobacter spp. (11.7\%; 2/17), Esch. coli (11.7\%; 2/17), Enterobacter spp. (5.8\%; 1/17), Klebsiella spp. (5.8\%; 1/17), and Streptococcus pneumoniae (5.8\%; 1/17). Similarly, Aspergillus spp. (34.5\%; 10/29) were the commonest among all fungi isolated followed by Fusarium spp. (20\%; 6/29), unidentified dematiaceous fungi (17.2\%; 5/29), Penicillium spp. (13.7\%; 4/29), Curvularia spp. (6.8\%; 2/29), Bipolaris spp $(3.4 \% ; 1 / 29)$ and Candida albicans $(3.4 \% ; 1 / 29)$.

Thirty-nine patients had history of trauma with vegetative matters, hairs, stone and other materials as compared to 45 who did not have trauma (Table 1). Majority i.e 66.7\% (26 of 39) of those having trauma as the predisposing factor developed moderate to severe degree of corneal

\section{Table 2: Etiological agents isolated $(n=42)$}

\begin{tabular}{|llc|} 
Bacterial and/or fungal growth & No of cases \\
& Name of the organism & 5 \\
& Staphylococcus aureus & 2 \\
Bacterial growth (N-13) & Acinetobacter spp. & 1 \\
& Escherichia coli & 2 \\
& Enterobacter species & 1 \\
& Klebsiella pneumoniae & 1 \\
& Streptococcus pneumoniae & 1 \\
& Aspergillus species & 9 \\
Fungal growth (N-25) & Fusarium species & 6 \\
& Unidentified dematiaceous fungus & 5 \\
& Penicillium & 2 \\
& Curvularia & 2 \\
Bipolaris species & 1 \\
& Staphylococcus aureus + Candida albicans & 1 \\
& Staphylococcus aureus + Aspergillus species & 1 \\
& Staphylococcus aureus +Penicillium & 1 \\
& Acinetobacter spp.+ Penicillium & 1 \\
\hline
\end{tabular}


ulceration as compared to only $20 \%$ (9 of 45) of those without any history of trauma (Table 3). This difference was found to be statistically significant $(\mathrm{p}<0.001)$.

\begin{tabular}{|c|c|c|c|}
\hline \multirow{4}{*}{$\begin{array}{l}\text { Trauma } \\
\text { No Trauma }\end{array}$} & $\begin{array}{l}\text { Mild } \\
\text { n(\%) }\end{array}$ & $\begin{array}{l}\text { Moderate to } \\
\text { severe, } \mathrm{n}(\%)\end{array}$ & Total \\
\hline & $13(39.3)$ & $26(66.7)^{*}$ & 39 \\
\hline & $36(80)$ & $9(20)^{*}$ & 45 \\
\hline & 49 & 35 & 84 \\
\hline
\end{tabular}

$* \mathrm{p}<0.001$

Table 4 depicts association between trauma and fungal or non-fungal origin of infectious keratitis. Interestingly, 20(68.9\%) of the 29 cases that had yielded fungal growth on culture had past history of trauma inflicted on to cornea. Contrary to this, only 19 (34.5\%) of the 55 who had non-fungal origin of keratitis had such history of trauma and this difference, too, was also found to be statistically significant $(\mathrm{p}=0.003)$.

Table 4: Fungal keratitis in patient with and without previous history of trauma

\begin{tabular}{|c|c|c|}
\hline & $\begin{array}{c}\text { History of } \\
\text { trauma }\end{array}$ & $\begin{array}{l}\text { No history } \\
\text { of trauma }\end{array}$ \\
\hline $\begin{array}{l}\text { Fungal growth on } \\
\text { culture (29) }\end{array}$ & $\begin{array}{c}20 \\
(68.95 \%)^{*}\end{array}$ & $9(31.1 \%)$ \\
\hline $\begin{array}{l}\text { No fungal growth on } \\
\text { culture (55) }\end{array}$ & $\begin{array}{c}19 \\
(34.5 \%) *\end{array}$ & $36(65.5 \%)$ \\
\hline Total & 39 & 45 \\
\hline
\end{tabular}

$* p=0.003$

It was noteworthy that significantly higher number of patients yielding fungal growth on culture, presented with moderate to severe form of ulcerative keratitis (20/29 i.e 68.9\%). In contrast to this, only $15(27.3 \%)$ of 55 who had no evidence of fungal growth on culture had moderate to severe keratitis (Table 5; $\mathrm{p}<0.001$ ).

Table 5: Relationship between ulcer severity and fungal etiology

\begin{tabular}{|lccc|}
\hline & Mild & $\begin{array}{c}\text { Moderate } \\
\text { to severe }\end{array}$ & Total \\
$\begin{array}{l}\text { Fungal growth } \\
\text { (29) }\end{array}$ & $\begin{array}{l}\text { (31.1\%) } \\
\text { No fungal growth }\end{array}$ & $20(68.9 \%)^{*}$ & 29 \\
(55) & $\begin{array}{l}(73.7 \%) \\
\end{array}$ & $15(27.3 \%)^{*}$ & 55 \\
& 49 & 35 & 84 \\
\hline
\end{tabular}

$* \mathrm{p}<0.001$
DISCUSSION

Corneal blindness is a major public health problem worldwide and infectious keratitis is one of the predominant causes. The main objective was to find out the microbial etiology of corneal ulcers and to determine the antibiotic susceptibility pattern of bacterial isolates. Besides, we also analyzed demographic profile of the patients and epidemiological factors prevailing in our locality.

Demographic data of the patients revealed that majority of them belonged to the age group of $41-60$ years (38/84, i.e $45.2 \%)$. Thus, a large number of subjects belonged to working age group and thus could have had higher chances to succumb to ocular trauma, which was the most common predisposing factor, observed in the present study. This observation was similar to that of Chowdhary et a ${ }^{15}$ who showed as high as $37 \%$ of cases of keratitis occurring in the age group 31- 40 years. It could be speculated that younger is the age group affected, greater could be socioeconomic consequences.

Of 84 patients studied, 50 (59.5\%) were females and $34(40.5 \%)$ were males. The infection ratio of male: female was found to be 1.4:1. Similar findings were noted by Suwal et al. ${ }^{16}$ in a study from Nepal. However, others reported a higher incidence of infectious keratitis in males as compared to females. ${ }^{17,18}$ The higher number of cases among females, in our study could be because of significant contribution of female population to the agricultural force as compared to males who quite often remain away for outdoor activities in search of employment. ${ }^{19}$

Thirty-three (39.3\%) of the subjects were farmers by occupation. In Nepal, majority of population is involved in agricultural work and various types of manual labors. Thus, they become more prone to injuries being exposed to dust and wind, dryness and heat for which they often have ocular surface abnormalities and poor ocular hygiene, which could promote development of microbial keratitis. This observation of ours was similar to that of Sharma et al..$^{20}$ Obviously, trauma was the most common risk factor accounting for $46 \%$ $(39 / 84)$ in this case. None of the study subjects in our series had history of contact lens wear.

It was interesting to observe that higher number of patients (20 of 29, i.e $68.95 \%$ ) in our series with fungal etiology had prior history of corneal injury (Table 4). Our results were in complete agreement with data reported earlier, ${ }^{14}$ which showed that trauma with vegetative matter, could predispose to ulcerative keratitis in $23-55 \%$ of their cases. Thus, it is relevant to mention at this point that fungi being ubiquitous, trauma due 
to vegetative or organic matter could help in the deposition of fungal spores on the injured cornea that might act as a good substrate for the spores to germinate and give rise to hyphae. The hyphal forms being invasive can traverse through the stroma producing severe ulcerative lesions. ${ }^{14,15}$

In this geographical location, seasonal variation of flare up of corneal ulcer was noticed between May to August, the period when agricultural activity was on its peak as it was the crop planting period. We observed another upsurge of cases in November and December, i.e the crop harvesting period. This seasonal trend seen in present series was similar to that shown by Basak et al. ${ }^{21}$ which could be accounted for the likelihood of frequent exposure to vegetative matter in the cornfields with easy facilitation for corneal injury.

As shown in Table 3, out of the 84 samples examined, culture positivity was seen in 42 (50\%). Among these 42; 25 (29.7\%) yielded fungal growth, 13 (30.1\%) yielded bacteria and the rest $4(4.7 \%)$ showed mixed growth. Overall there were 17(20.2\%) bacterial isolates and 29 (34.5\%) fungal isolates. Aspergillus spp. (10/29) were the commonest among fungi isolated followed by Fusarium spp., 20 \% (6/29). Aspergillus spp. had been incriminated as the commonest fungal agents of the infectious keratitis in the past as per the documented reports from parts of northern India and Nepal. ${ }^{11,14}$ On the contrary, Fusarium spp. the common as reports from southern parts of India and other tropical countries like Ghana. ${ }^{7,22,23}$

Ganguly et al. ${ }^{23}$ from Nepal found Fusarium, as the commonest fungus isolated i.e. among $32.0 \%$ of their cases, followed by unidentified dematiaceous species in $22.0 \%$ cases and Curvularia species in 18.0\%. Fusarium species happen to be common plant pathogens particularly of cereal crops and saprophytes of plant debris found in soil. The higher accountability of Fusarium noted in some geographical locations like southern parts of India and Ghana may be due to widespread cereal crop cultivation and ecological condition, favoring the fungus to flourish in those geographical areas.

Among bacterial keratitis cases, Staph. aureus, (47\%; 8/17) was commonest isolates followed by Pseudomonas (11.7\%; 2/17). All the strains of Staphylococci were sensitive to amikacin and moxifloxacin. Amongst the Staph. aureus $5 / 8$ were methicillin sensitive and $3 / 8$ were methicillinresistant. Out of 3 MRSA, 2 isolates were resistant to ciprofloxacin and 1 was resistant to levofloxacin. All the isolates of Esch. coli $(\mathrm{n}=2)$ Klebsiella spp. $(\mathrm{n}=2)$ and Pseudomonas $(\mathrm{n}=2)$ were sensitive to the whole panel of antibiotics tested. Acinetobacter $(n=1)$ was sensitive to all except chloramphenicol. Enterobacter spp. $(\mathrm{n}=1)$ was sensitive to all except cefazolin. Strept. pneumoniae $(\mathrm{n}=1)$, however was also sensitive to all the antibiotics. In this study, all the bacterial isolates (Gram positive and Gram negative) were susceptible to fourth generation quinolone moxifloxacin, which is often chosen as the antibiotic of choice by many clinicians, including us, for treating bacterial keratitis. Ranjini and collegues $^{24}$ from India also reported that all their 52 bacterial isolates (both gram positive and gram negative) from 117 culture positive keratitis cases were sensitive to gatifloxacin.

In conclusion, this study showed that trauma with vegetative matter was the most common predisposing factor especially for fungal keratitis. Fungal etiology accounted for more severe form of ulcerative lesions. In the light of changing trends in the etiology of infectious keratitis, and in the susceptibility patterns of the etiologic agents, it is advocated to have routine surveillance of culture and sensitivity testing of the keratitis causing pathogens in order to provide appropriate antimicrobial therapy.

\section{REFERENCES}

1. Whitcher JP, Srinivasan M, Upadhyay MP. Corneal blindness: A global perspective. Bull World Health Organ 2001; 79: 214-21.

2. Bhadange Y, Sharma S, Das S, Sahu SK. Role of liquid culture media in the laboratory diagnosis of microbial keratitis. Am J Ophthalmol 2013; 156: 745-51.e2.

3. Ahmed S, Ghosh A, Hassan SA, Tarafdar S, Ruhul MD, Miah A. Predisposing Factors and Aetiologic Diagnosis of Infectious Corneal Ulcer. Bangladesh J Med Microbiol 2010; 04: 28-31.

4. Guidelines for the Management of Corneal Ulcer at Primary, Secondary and Tertiary Care health facilities in the South- East Asia Region, World Health Organization Bulletin. 2004; p6-8.

5. Smith GTH, Taylor HR. Epidemiology of corneal blindness in developing countries. Refractive Corneal Surg 1991; 7: 436-9.

6. Shah A, Sachdev A, Coggon D, Hossain P. Geographic variations in microbial keratitis: an analysis of the peer-reviewed literature. Br J Ophthalmol 2011; 95: 762-7.

7. Leck AK, Thomas PA, Hagan M et al. Aetiology of suppurative corneal ulcers in Ghana and south India, and epidemiology of fungal keratitis. $\mathrm{Br} J$ Ophthalmol 2002; 86: 1211-5. 
8. Schaefer F, Bruttin O, Zografos L, Guex-Crosier Y. Bacterial keratitis: a prospective clinical and microbiological study. $\mathrm{Br} J$ Ophthalmol 2001; 85: 842-7.

9. Alexandrakis G, Alfanso EC, Miller D. Shifting trends in bacterial keratitis in South Florida and emerging resistance to Fluoroquinolones. Ophthalmol 2000; 107: 1497-502.

10. Nayak N: Fungal infections of the eye - laboratory diagnosis and treatment: Nepal Med Coll J 2008; 10: 48-63

11. Bauer AW, Kerby WMM, Sherris JC, Turck. M. Antibiotic Susceptility testing by a standardized single disc method. Am J Clin Pathol 1966; 45: 493-6.

12. Forbes B.A Bailey and Scott's Diagnostics Microbiology, $10^{\text {th }}$ ed Mosby, St Louis, 1998.

13. Baum J, Barza M: Infectious Diseases. Infections of the eye; in Gorbach SL, Bartlett JE, Blacklow NR (eds): Philadelphia, Saunders, 1992: 1134-51.

14. Mohan M, Sangawe LF, Mahajan VM. Pathogenesis of experimentally produced corneal ulcer in rabbits. Ann Opthalmol 1984; 16: 246-52.

15. Chowdhary A, Singh K. Spectrum of fungal keratitis in North India. Cornea 2005; 24: 8-15

16. Suwal S, Bhandari D, Thapa P, Shrestha MK, Amatya J. Microbiological profile of corneal ulcer cases diagnosed in a tertiary care ophthalmological institute in Nepal. BMC Ophthalmol 2016: 16: 209. DOI 10.1186/s12886-016-0388.

17. Lavaju P, Arya SK, Khanal B, Amatya R, Patel S. Demograhic pattern, clinical features and treatment outcome of patients with infective keratitis in the eastern region of Nepal. Nepal $J$ Ophthalmol 2009; 1: 101-6.

18. Dhakhwa K, Sharma MK, Bajimaya S, Dwivedi AK, Rai S. Causative organisms in microbial keratitis, their sensitivity pattern and treatment outcome in western Nepal. Nepal J Ophthalmol 2012; 4: 119-27. Available from:http://www. epjoph.org.np/pdf/ NEPjOPH_201201136.pdf.

19. Rai PG, Chaudhary M, Sharma AK et al. Direct microscopy in suppurative keratitis: a report from tertiary level hospital in Nepal. Nepal J Ophthalmol 2016; 8: 128-38.

20. Sharma B, Gupta R, Som V, Kubrey SS, Anand R, Kumar K. Clinical profile of microbial keratitis causes and contributing factors. J Evol Med Dent Sci 2013; 2: 23.

21. Basak SK, Basak S, Mohanta A, Bhowmick A. Epidemiological and Microbiological Diagnosis of Suppurative Keratitis in Gangetic West Bengal, Eastern India. Indian J Opthalmol 2005; 53: 17-22.

22. Tewari A, Sood N, Vegad MM, Mehta DC. Epidemiological and microbiological profile of infective keratitis in Ahmedabad. Indian $J$ Opthalmol 2012; 60: 267-72.

23. Ganguly S, Salma KC, Kansakar I, Sharma M, Bastola P, Pradhan R. Pattern of fungal isolates in cases of corneal ulcer in the western periphery of Nepal. Nepal J Ophthalmol 2011; 3: 118-22.

24. Ranjini CY, Vandana VW. Microbial Profile of Corneal Ulcers in a Tertiary Care Hospital in South India. J Opthalmic Vis Res 2016; 11: 363-7. 